\title{
Aydın İ Merkezinde turunç Citrus aurantium L. (Rutaceae) ağaçlarında bulunan Coccoidea üst familyası ile Aphididae ve Aleyrodidae familyaları (Hemiptera)' na bağlı türlerin saptanması, bulaşma oranlarının ve doğal düşmanlarının belirlenmesi
}

Determination of species from Coccoidea superfamily, and Aphididae and Aleyrodidae families (Hemiptera), their infestation rate and natural enemies on sour orange Citrus aurantium L. (Rutaceae) in Aydın province

\section{Hüseyin YERLIKAYA $^{1 *}$ Hüseyin BAŞPINAR ${ }^{2}$ Eyyüp Mennan YILDIRIM ${ }^{3}$ Summary}

It was aimed to determine the pest species, their infection rate and their natural enemies on sour orange grown for landscape on Boulevards in three different district of the city center namely, Muğla Boulevard, Atatürk Boulevard and Batı Gazi Boulevard, and samplings were conducted in 2012 and 2013. Leaves and shoots were sampled on the trees and examined under stereo binocular microscope every 15 days in the laboratory to determine their infestation rate. Additionally, adult predators and parasitized pest individuals were also collected during sampling to determine the natural enemies. As a result, Coccus hesperidum (Linnaeus), Ceroplastes rusci (Linnaeus) and Aonidiella aurantii (Maskell) were determined in Coccoidea (Hemiptera) superfamily. Four aphid species, Aphis spiraecola (Patch), Aphis gossypii (Glover), Toxoptera aurantii (Boyer de Fonscolombe), and Myzus (Nectarosiphon) persicae (Sulzer) (Hemiptera: Aphididae) were also identified. Adalia fasciatopunctata (Mulsant), Oenopia (Synharmonia) conglobata (Linnaeus), Adalia bipunctata (Linnaeus), and Coccinella septempunctata (Linnaeus) (Coleoptera: Coccinellidae), and additionally Binodoxy angelicae and Lysiphlebus testaceipes (Hymenoptrera: Braconidae) were found as natural enemies on aphids. Aleurothirixus floccosus was sampled as whitefly, and Cales noacki Howard (Hymenoptera: Aphelinidae) was found to be natural enemy on A. floccosus. The parasitization was the highest in September in both study periods.

Key words: Coccoidae, Aphididae, Aleyrodidae, Aydın, sour orange

\section{Özet}

Bu çalışmada, 2012-2013 yıllarında, Aydın merkezde; Muğla Bulvarı, Atatürk Bulvarı ve Batı Gazi Bulvarı olmak üzere üç ayrı bölgede peyzaj amaçlı kullanılan turunç ağaçlarında bulunan zararlıların, bulaşma oranlarının ve doğal düşmanların belirlenmesi amaçlanmıştır. Bunun için, 15 gün arayla yaprak ve sürgün örnekleri alınmıştır. Örnekler laboratuvara getirilerek stereo mikroskop altında incelenmiş ve bulaşma oranları hesaplanmıştır. Ayrıca, örneklemeler sırasında ergin avcı böcekler, parazitoitli bireyler laboratuvara getirilerek doğal düşmanlar saptanmıştır. Sonuç olarak Coccoidea (Hemiptera) üst familyasına bağlı Coccus hesperidum (Linnaeus), Ceroplastes rusci (Linnaeus) ve Aonidiella aurantii (Maskell) türleri tespit edilmiştir. Turunç ağaçlarında diğer bir zararlı grubu Aphis spiraecola (Patch), Aphis gossypii (Glover), Toxoptera aurantii (Boyer de Fonscolombe) ve Myzus persicae (Sulzer) (Hemiptera: Aphididae) olmak üzere dört farklı yaprakbiti türü tespit edilmiştir. Yaprakbitlerinin doğal düşmanı olarak; Adalia fasciatopunctata (Mulsant), Oenopia (Synharmonia) conglobata (Linnaeus), Adalia bipunctata (Linnaeus), Coccinella septempunctata (Linnaeus) (Coleoptera: Coccinellidae) ile Binodoxy angelicae ve Lysiphlebus testaceipes (Hymenoptrera: Braconidae) türleri belirlenmiştir. Aleyrodidae familyasından Aleurothirixus floccosus saptanmıştır. A. floccosus' un doğal düşmanı olarak da Cales noacki tespit edilmiştir. Her iki çalışma dönemi boyunca $A$. floccosus' un C. noacki ile parazitlenme oranının eylül ayında en yüksek düzeyde olduğu görülmüştür.

Anahtar sözcükler: Coccoidae, Aphididae, Aleyrodidae, Aydın, turunç

1 Adnan Menderes Üniversitesi, Sultanhisar Meslek Yüksekokulu, 09470, Sultanhisar, Aydın

2 Adnan Menderes Üniversitesi Ziraat Fakültesi Bitki Koruma Bölümü,09970, Aydın

3 Adnan Menderes Üniversitesi Ziraat Fakültesi Tarımsal Biyoteknoloji Bölümü,09970, Aydın

* Sorumlu yazar (Corresponding author) email: huseyin.yerlikaya@adu.edu.tr

Alınış (Received): 30.10.2015 Kabul ediliş (Accepted): 28.03.2016 
Aydın İı Merkezi nde turunç Citrus aurantium L. (Rutaceae) ağaçlarında bulunan Coccoidea üst familyası ile Aphididae ve

\section{Giriş}

Turunç, Citrus aurantium L. (Rutaceae) diğer turunçgil tür ve çeşitleri gibi meyve üretimi açısından yaygın olarak tarımı yapılan bir ürün değildir. Ancak, birçok Akdeniz ülkesinde olduğu gibi ülkemizde de yerleşim yerlerindeki açık alanlarda park ve süs bitkisi olarak değerlendirilmektedir. Aydın ilinde de şehir merkezinde gerek yol ve bulvarlarda ve gerekse park ve bahçelerde yaygın olarak bulunmaktadır. Son yıllarda bu ağaçlarda zararlılardan kaynaklanan kuruma, çalılaşma ve fumajin gibi belirtilerin yaygınlaştığı yönünde şikayetler söz konusudur. Başlangıçta, turunç ağaçlarındaki bu sorunlara neden olan başlıca zararlının Turunçgil pamuklu beyazsineği Aleurothirixus floccosus (Maskell) (Hemiptera: Aleyrodidae) olduğu düşünülmekteydi. Ancak, laboratuarımıza getirilen örneklerin değerlendirilmesi sonucunda yukarıda belirtilen bu zararının yanı sıra özellikle Coccoidea üst familyası ile Aphididae ve Aleyrodidae familyaları (Hemiptera)' na bağlı birçok zararlılar saptanmıştır.

Bu zararlıların genel olarak bitki özsuyunu emerek beslendikleri, birçoğunun beslenmeleri sırasında salgıladıkları bitki özsuyu üzerinde saprofit mantar gelişimine bağlı olarak fumajin oluşturdukları, gömlek değiştirmeleri ile yaprak ve bitki sürgünlerinde mumsu artıklar oluşturdukları ve bazı türlerinin de virüs vektörü olduğu bilinmektedir (Lodos, 1986).

Söz konusu bu gibi zararlılar üzerinde turunçgil bahçelerinde gerçekleştirilmiş bir çok çalışma bulunmaktadır (Öncüer, 1974; Soylu, 1980; Uygun et al., 2001; Özer \& Kısmalı, 2003;). Turunçgillerde yaklaşık 65 üzerinde beyazsinek türü bilinmesine karşın, bunlardan 15 kadar türün dünyanın değişik bölgelerinde ekonomik önemde zarar yaptığı belirtilmiştir (Ulusoy \& Uygun, 1996). Türkiye' de ise turunçgillerde ekonomik olarak zararlı olan ve bilinen en eski tür Turunçgil beyazsineği, Dialeurodes citri (Ashmead) olup Türkiye' de ilk olarak 1967' de Doğu Karadeniz Bölgesi' nde, 1972' de Ege Bölgesi' nde ve 1976 yılında Doğu Akdeniz Bölgesi'nde saptanmıştır (Özer \& Kısmalı, 2003). Daha sonra bu türe ilave olarak Defne beyazsineği Parabemisia myricae (Kuwana) tespit edilmiş olup, ilk olarak 1982 yılında Akdeniz Bölgesi' nde ve 1988 yılında da Ege Bölgesi turunçgil alanlarında zararlı olduğu bildirilmiştir (Öncüer \& Yoldaş, 1988). İlerleyen yıllarda bu beyazsinek türlerine iki yeni tür daha eklenmiştir. Bunlardan ilki $A$. floccosus ve ikincisi Turunçgil ipek beyazsineği Paraleyrodes minei Laccarino türleri olup, ilk kez Akdeniz Bölgesi' nde saptanmıştır (Ulusoy \& Uygun, 1996).

Turunçgillerde ekonomik zarara neden olan bir diğer zararlı grubu ise kabuklubitlerdir ve ağaçların gövde, dal, sürgün, yaprak ve meyvelerinde emgi yaparak zarar oluştururlar (Uygun et al., 2010). Bu üst familyada ülkemizde 267 tür bildirilmiştir (Kaydan et al., 2007). Turunçgillerin ana zararlısı durumunda olan Kırmızı kabuklubit Aonidiella aurantii (Maskell) (Hemiptera: Coccomorpha: Diaspididae), turunçgillerin meyve ve yapraklarında olduğu kadar gövde, dal ve sürgünlerinde de zarar yapmaktadır. Popülasyonun yüksek olduğu durumlarda mücadele iyi yapılmamış ise meyvelerin kirli kalması, meyve ve yapraklarda döküm, dalların ve hatta ağacın tamamının kuruması gibi zararlar ortaya çıktığı belirtilmiştir (Aytaş et al., 1997).

Coccoidea üst familyasında bir diğer zararlı grup unlubitler olarak bilinen Pseudococcidae familyası bulunmaktadır. Bu familyadaki bireylerin vücutları mumlu bir maddeyle kaplıdır. Bu familyada yer alan Planococcus citri (Risso) ülkemizde ve dünyada turunçgillerin en önemli zararlılarındandır. Turunçgil unlubiti olarak adlandırılan bu zararlı polifag bir türdür (Lodos, 1986).. Ülkemizde ekonomik açıdan turunçgillerde zarar meydana getiren bu türün en fazla greyfurt ve portakalı tercih ettiği belirtilmiştir (Ülgentürk et al., 2006). Bu zararlı, bitkinin yaprak, sap, meyve ve köklerinde bitki özsuyunu sokup emmek suretiyle beslenmektedir. Turunçgillerde meyvenin sapla birleştiği yerlerde emgi yaparak meyve kalitesini düşürmekte ve sap dipleri zayıflayan meyvelerin dökülmesine neden olmaktadır (Lodos, 1986).

Turunçgillerde zarar yapan bir diğer familya Coccidae (Yumuşak kabuklubitler)' dir. Yapılan çalışmalarda ülkemizde turunçgillerde en çok görülen türler; Coccus hesperidum (Linnaeus), Coccus pseudomagnoliarum (Kuwana), Ceroplastes rusci (Linnaeus), Ceroplastes floridensis (Comstock) olarak belirlenmiştir (Öncüer, 1974; Zümreoğlu et al., 1985; Şişman \& Ülgentürk, 2010). 
Yaprakbitleri (Hemiptera: Aphididae) de turunçgillerde önemli bir zararlı grubu oluşturmaktadır. Türkiyede turunçgil bahçelerinde; Aphis gossypii (Glover), Aphis spiraecola (Patch), Aphis craccivora (Koch), Myzus persicae (Sulzer), Toxoptera aurantii (Boyer de Fonscolombe) olmak üzere beş yaprakbiti türü belirlenmiştir (Yumruktepe \& Uygun, 1994). Bunlar daha çok genç bahçe ve fidanlıklarda zararlı olmaktadır. Sokucu emici ağız yapısına sahip olan yaprakbitleri bitki özsuyunu emerek doğrudan zarar yaptıkları gibi, salgıladıkları tatlı maddeler üzerinde saprofit fungusların gelişmesi sonucu fumajine neden olarak bitkinin fotosentez yapmasına engel olmakta ve bitkide gelişme geriliğine yol açmasıyla da dolaylı olarak zararlı olmaktadırlar. Bunların yanında virüs ve benzeri hastalıkları taşıyarak da önemli zarar oluşturduğu bildirilmektedir (Gücük \& Yoldaş, 2000; Uygun et al., 2010).

$\mathrm{Bu}$ çalışmanın amacı, Aydın ili Merkez ilçede park, bahçe ve bulvarlarda süs bitkisi olarak kullanılan turunç ağaçlarında Coccoidea üst familyası ile Aphididae ve Aleyrodidae familyalarına bağlı zararlıların saptanması, bulaşma oranlarının ve doğal düşmanlarının belirlenmesidir.

\section{Materyal ve Yöntem}

Bu çalışma Aydın Merkezde; Muğla Bulvarı, Atatürk Bulvarı ve Batı Gazi Bulvarı olmak üzere Aydın İlini temsil edecek üç ayrı bölgede 2012-2013 yıllarında yürütülmüştür. Bu bölgelerdeki turunç ağaçlarında bulunan zararlı ve doğal düşmanların belirlenmesi amacıyla örneklemeler yapılmıştır. İlk örnekleme Nisan 2012 tarihinde başlatılmış, 15 gün arayla periyodik olarak devam edilmiş ve Aralık 2013'de son örnekleme yapılmıştır. Örneklemeler ve sayımlar söz konusu zararlıların etkili olduğu aylar arasında (Nisan-Aralık) 2012-2013 yıllarında iki yıl süreyle yapılmıştır. Çalışmanın sonunda iki yıllık veriler kullanılmıştır.

\section{Örneklerin alınması}

Coccoidea üst familyası ile Aleyrodidae ve Aphididae familyalarına bağlı bireylerin saptanması için budama makası yardımıyla, yukarıda belirtilen her bölgeden rastgele 10 ağaç seçilmiş ve her ağaçtan tesadüfi olarak 20-25 cm'lik bir sürgün alınmıştır, Böylece örnekleme yapılan 3 bölgeden toplamda 30 adet sürgün toplanmıştır. Alınan yaprak ve sürgün örnekleri ayrı ayrı paketlenmiş, kese kağıtlarına sarılarak etiketlenmiş ve polietilen torbaların içinde laboratuvara getirilmiştir.

Doğal düşmanlardan predatör türlerin saptanması için, örnekleme alanlarındaki her ağacın etrafında 2-3 dk. dolaşarak gözle inceleme yapılmış ve görülen erginler el ile ya da ağız aspiratörü ile toplanmıştır. Ergin öncesi dönemde olan bireyler ise, pens yardımıyla kültür kutularına içerisinde besinleriyle birlikte laboratuvara getirilmiş ve kültüre alınmıştır. Ayrıca parazitoitli olduğundan şüphe edilen bireylerin bulunduğu bitki örnekleri de parazitoit çıkarma kutularına konularak, parazitoitler elde edilmiştir. Bu bitki örnekleri üzerindeki parazitoitli olan ve olmayan birey sayılarından da parazitlenme oranları hesaplanmıştır.

Bunun yanı sıra, örnekleme ağaçlarında avcı türlerin saptanması amacıyla, örnekleme yapılan bulvarların her birini temsil edecek şekilde tesadüfen seçilmiş ağaçların (10 ağaç) dört yönünden birer dalına sopa ile beş kez vurularak predatörlerin japon şemsiyesine düşmeleri sağlanmıştır. Böcekler daha sonra öldürülerek etiketlenmek üzere laboratuvara getirilmiştir.

Bu şekilde elde edilen örneklerden iğnelenebilecek olanlar iğnelenerek etiketlenmiş ve teşhise hazır hale getirilmiştir. Parazitoitler kuru olarak her biri bir eppendorph tüpüne olmak üzere ayrı ayrı konulmuş ve etiketlenmiştir. Örneklemeler sonucunda gerek alınan sürgünlerden ve gerekse doğrudan toplanan örnekler iğnelenmeye uygun değil ise \% 70' lik alkole konularak etiketlenmiştir. Hazırlanan bu örnekler teşhis edilmek üzere konu uzmanlarına gönderilmiştir. Parazitoitli Aleurotrixus floccossus (Maskell) (Hemiptera: Aleyrodidae) bireylerinden elde edilen parazitoitler daha önce teşhisleri yapılmış bireylerle karşılaştırılmış ve Cales noacki (Howard) (Hymenoptera: Aphelinidae) olarak teşhisleri tarafımızca yapılııştır. Bu parazitoit $A$. floccossus' a spesifik olup (Chermiti \& Onillon,1995), bu güne kadar zararlı üzerinde saptanan yaygın bir türdür (Vatansever \& Ulusoy, 2005). 
Aydın İı Merkezi nde turunç Citrus aurantium L. (Rutaceae) ağaçlarında bulunan Coccoidea üst familyası ile Aphididae ve

Aleyrodidae familyaları (Hemiptera)' na bağlı türlerin saptanması, bulaşma oranlarının ve doğal düşmanlarının belirlenmesi

\section{Coccoidea üst familyası ile Aleyrodidae ve Aphididae familyalarına bağlı türlerin bulaşıklık oranlarının belirlenmesi}

Sürgün ve yapraklar üzerindeki zararlıların saptanması için getirilen bitki örnekleri laboratuvarda tek tek gözle incelenmiştir. Gerektiğinde stereo binoküler mikroskoptan yararlanılmıştır. Bir sürgün üzerinde Coccoidea üst familyasından zararlılar teşhis sonuçları alındıktan sonra dış morfolojik karakterlerine göre tür düzeyinde gözle birbirinden ayırt edilebildiği için ve bunun yanı sıra Aleyrodidae familyasından da sadece bir tür (Aleurotrixus floccossus (Maskell)) saptandığı için, tarafımızca tür bazında bulaşıklık açısından bir değerlendirme yapılabilmiştir. Böylece bu türlerin bulaşıklık oranları ayrı ayrı verilmiştir. Ayrıca bunlara ek olarak, A. floccossus' un biyolojik dönemlerine ilişkin gözlem ve sayımlar da yapılmış ve böylece daha ayrıntılı bir çalışma gerçekleştirilmiştir. Bunun için getirilen sürgünlerden her bir bölge için ayrı ayrı olmak üzere $A$. floccossus ile bulaşık 10' ar yaprak üzerinde yumurta, nimf, pupa ve pupa gömleği sayımları yapılmış ve her bir biyolojik dönem için ayrı ayrı olmak üzere bunların ortalaması verilmiştir. Buna karşın, Aphididae familyasına bağı türler gözle veya stereo binoküler mikroskop altında dış morfolojik özellikleriyle tarafımızca ayırt edilemediğinden bulaşıklık açısından topluca Aphididae türleri olarak değerlendirilmiştir. Bulaşıklık açısından değerlendirmelerde, sürgün ya da yaprak üzerinde bir zararlı var ise, o materyal zararlı tür ile bulaşık, bunun tersine herhangi bir zararlı yok ise temiz olarak değerlendirilmiş ve buna göre bulaşıklık oranı 30 sürgün üzerinden saptanmıştır. Bir sürgün üzerinde birden fazla zararlı türün bulunduğu durumlarda da her bir tür için bulaşma oranları ayrı ayrı hesaplanarak verilmiştir.

\section{Araştırma Sonuçları ve Tartışma}

\section{Coccoidea üst familyası ile ilgili bulgular}

2012-2013 yıllarında yapılan örneklemeler ve sayımlar sonucunda Aydın merkezdeki turunç ağaçlarında, Coccoidea (Hemiptea) üst familyasına bağlı; Coccus hesperidum (Linnaeus), Ceroplastes rusci (Linnaeus) (Coccidae) ve Aonidiella aurantii (Maskell) (Diaspididae), Planococcus citri (Risso) (Pseudococcidae) ve Icerya purchasi Maskell (Margarodidae) olmak üzere beş farklı tür olduğu tespit edilmiştir. Çalışmanın yürütüldüğü her iki yılda da C. hesperidum, C. rusci ve A. aurantii' nin mevsim boyunca bulaşıklık durumu Şekil 1 ve Şekil 2' de gösterilmiştir. Buna karşın gerek $P$. citri ve gerekse $I$. purchasi bulaşmaları örnekleme süresince çok düşük düzeylerde seyrettiği için grafik haline getirilememiştir. Önceki yıllarda Ege Bölgesi'nde turunçgil bahçelerinde yapılan bir çalışmada, Coccus türlerinden hem $C$. pseudomagnoliarum ve hem de $C$. hesperidum tespit edildiği bildirilmiştir (Öncüer, 1974). Ancak Aydın' daki turunç ağaçlarında yapılan bu çalışmada C. pseudomagnoliarum' a rastlanmamıştır. Bu farklıığın, daha önceki çalışmanın yürütüldüğü turunçgil bahçelerinde örneklemelerin turunç dışındaki diğer turunçgil tür ve çeşitlerinde yapılmış olmasından kaynaklanmış olabileceği düşünülmektedir. Bunun yanı sıra, çalışmanın yürütüldüğü turunç ağaçlarının şehir içerisinde tarım alanlarının uzağında oluşu ve şehir içerisinde tek tek birbirinden oldukça uzak mesafelerde dikilmiş olması da yeni zararılıların bulaşmalarını güçleştirici bir etken olarak değerlendirilebilir.

Şekil 1' de 2012 yılına ait bulaşıklık oranları verilmiştir. Buna göre, C. hesperidum mevsim başında yüksek bir bulaşıklık oranı göstermesine karşın, zaman ilerledikçe bu oran düşmüştür. Bunun yerine, $C$. rusci' nin bulaşıklık oranı yükselmiştir. C. hesperidum en yüksek bulaşıklık oranına 29. 06. 2012 tarihinde ulaşmış ve bulaşıklık oranı bu tarihte \% 45 düzeyinde gerçekleşmiştir. Bu tarihten sonra bir süre bulaşıklık oranı azalmış ancak mevsim sonlarına doğru oran artış göstererek \% 26 düzeyine ulaşmıştır. C. rusci ise en yüksek bulaşıklık oranına \%40' lık bir değerle 14. 10. 2012 ve 30. 11. 2012 tarihlerinde ulaşmıştır. Diğer zararlı $A$. aurantii ise 14. 09. 2012 tarihinde \% 32,5' lik bir bulaşıklık oranına ulaşmıştır. Mevsim sonunda bu oran azalarak \% 7 düzeyine kadar düşmüştür. 


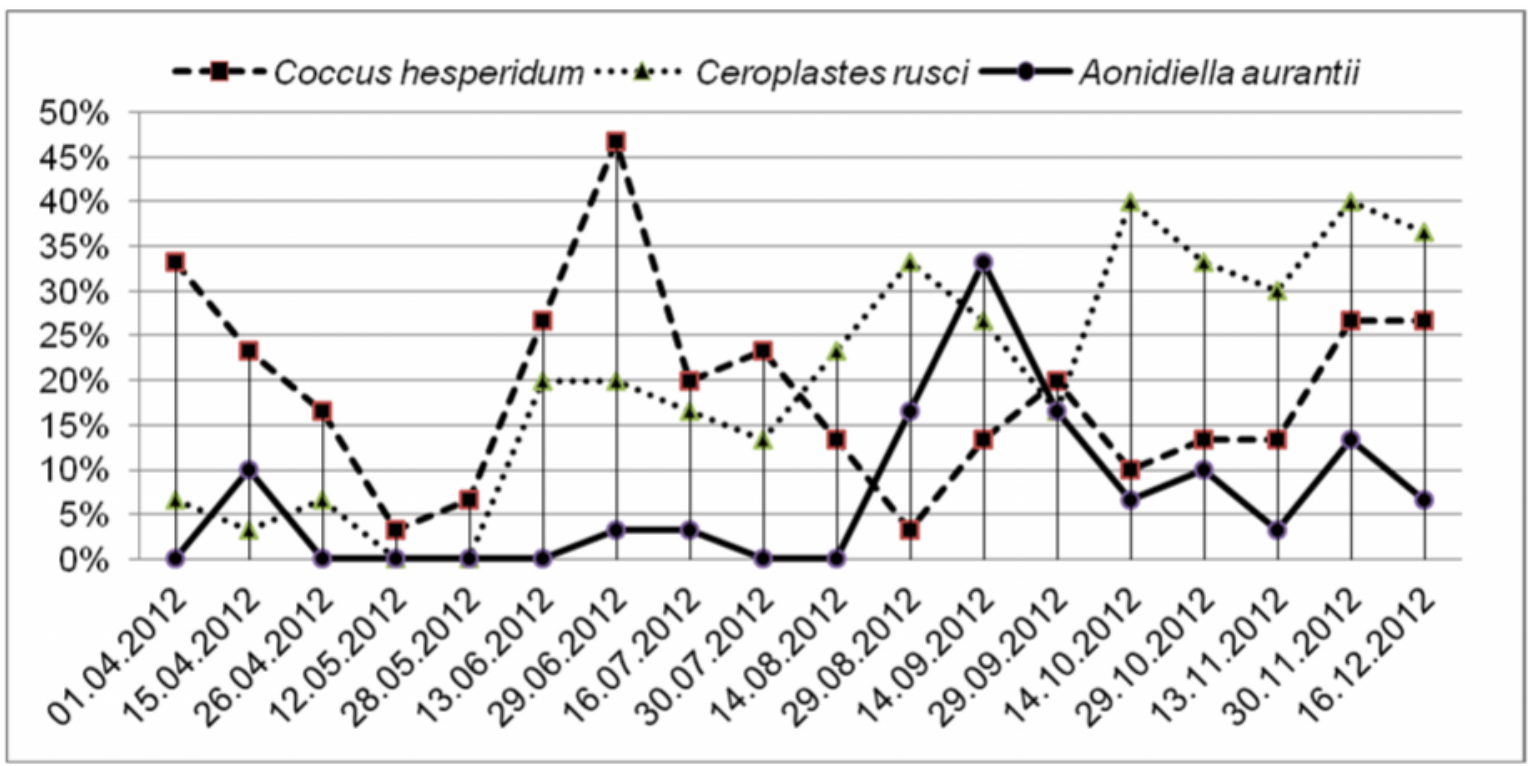

Şekil 1. Aydın il merkezindeki turunç ağaçlarında Coccus hesperidum, Ceroplastes rusci ve Aonidiela aurantii' nin bulaşıklık oranları (2012).

Şekil 2' de 2013 yılına ait bulaşıklık oranları verilmiştir. Buna göre, C. hesperidum mevsim başında daha yüksek bir bulaşıklık oranı göstermesine karşın, zaman ilerledikçe bu oran inişli çıkışlı bir hal almıştır. C. rusci ve $A$. auranti' nin bulaşıklık oranları zamanla yükselmiştir. $C$. hesperidum en yüksek bulaşıklık oranına \% 22,5' luk değer ile 05. 04. 2013 tarihinde ulaşmıştır. Mevsim sonunda ise C. hesperidum' un bulaşıklık oranı \% 15 düzeyinde bulunmuştur. C. rusci için en yüksek bulaşıklık oranı ise \% 26' lık bir değerle 22.11. 2013 tarihinde görülmüştür. A. aurantii ise 20. 09.2013 tarihinde \% 43 lük bir bulaşıklık oranına ulaşmıştır. Mevsim sonuna doğru bu değer bir miktar azalarak \% 25 düzeyinde kalmıştır.

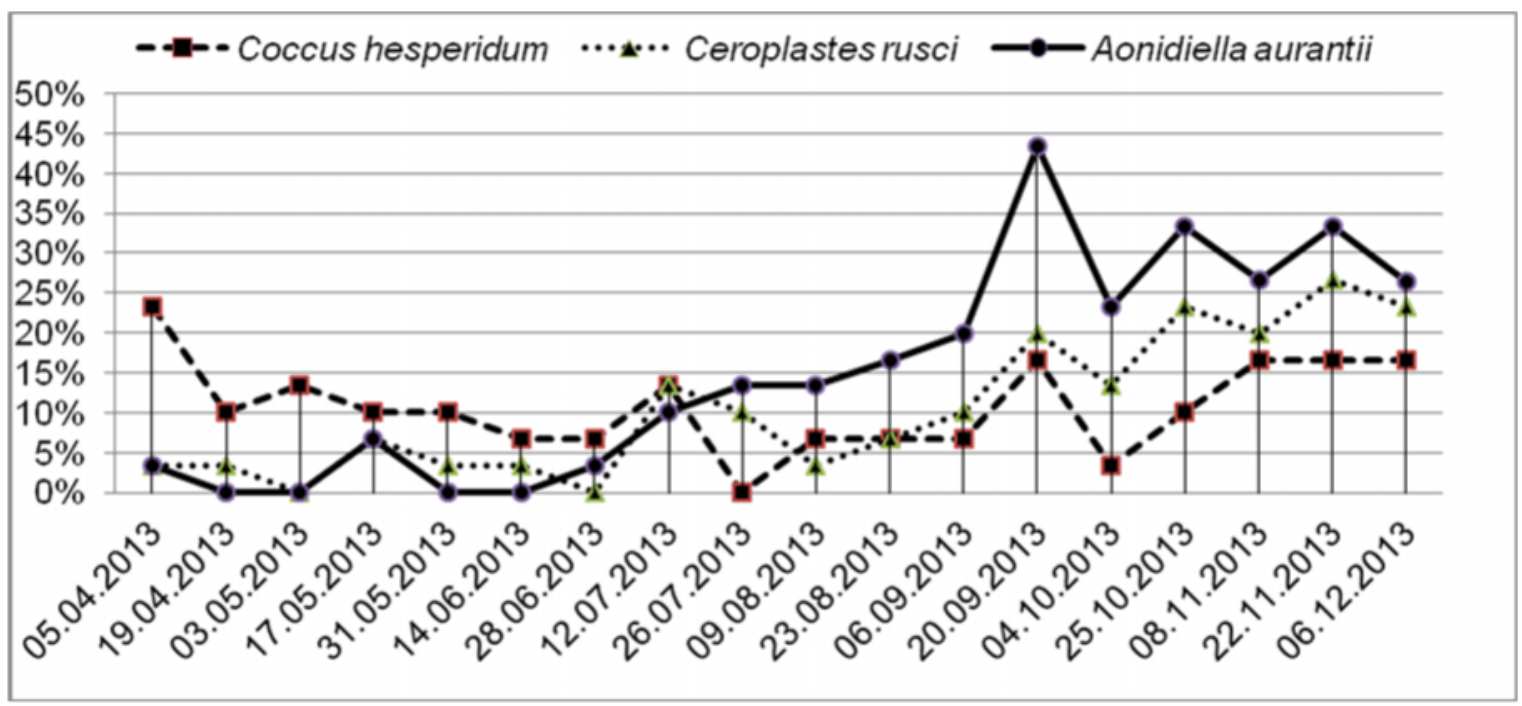

Şekil 2. Aydın il merkezindeki turunç ağaçlarında Coccus hesperidum, Ceroplastes rusci ve Aonidiela aurantii' nin bulaşıklık oranları (2013). 
Aydın İ Merkezi nde turunç Citrus aurantium L. (Rutaceae) ağaçlarında bulunan Coccoidea üst familyası ile Aphididae ve

Genel bir değerlendirme yapılacak olursa, her iki yılda da mevsim başında $C$. hesperidum' un bulaşıklık oranı yüksek bulunmuştur. 2012' de bu oran daha yüksek iken 2013 yılında daha düşük olarak belirlenmiştir. C. rusci' nin bulaşıklık oranı da benzer şekilde genel olarak 2012 yılında, 2013 yılına göre daha yüksek tespit edilmiştir. A. aurantii ise 2013' de, 2012 yılına göre daha yüksek bulaşıklık oranına ulaşmıştır. Gerek $C$. hesperidum ve $C$. rusci ve gerekse $A$. aurantii' nin bulaşık oranlarının yıllar itibarıyla farklı oluşlarının nedeni ile ilgili kesin bir kanıya varmak elde edilen bu verilerle mümkün olamamıştır. Ancak, genel olarak yıllar itibarıyla aynı yerde ve aynı bitkilerde böcek popülasyonları arasında ortaya çıkan farklılıklar için birçok neden olabilir. Bu nedenlerden birisi doğal düşman dinamikleridir. Aydın İli içerisinde, tarımsal alanda bulunmayan ve birbirinden belirli bir mesafe ile dikilmiş bu turunç ağaçlarında yerleşik bir doğal düşman popülasyonu tespit edilememiştir. Dolayısıyla, zararlının çıkışından sonra çevredeki tarımsal alanlardan gelen doğal düşmanların zaman içerisindeki popülasyon değişimleri yıllara göre farklılık gösterebilir. Bunun yanı sıra, turunç ağaçlarına doğal düşmanların geliş zamanları da farklı olabilir. Bu durum söz konusu zararlı popülasyonlarının düzeyini etkilemektedir. Ayrıca, yıllar itibarıyla, hem hava sıcaklığı ve hem de nem düzeyleri hem zararlı ve hem de bunlar üzerinde beslenen yararlı popülasyonlarını etkileyerek yıllar arasında farkların ortaya çıkmasına neden olabilmektedir. Bunun yanı sıra, sivrisinek mücadelesinde kullanılan pestisitler ve uygulama zamanları da her yıl değişmektedir. Bunun sonucunda da, sivrisinek ilaçlamaları sırasında, turunç ağacı üzerinde bulunan zararlı ve yararlı popülasyonlarının da farklı etkilenmiş olabileceği düşünülmektedir.

\section{Aphididae familyası ile ilgili bulgular}

Aphididae (Hemiptera) familyasından Aphis spiraecola (Patch), Aphis gossypii (Glover), Toxoptera aurantii (Boyer de Fonscolombe) ve Myzus (Nectarosiphon) persicae (Sulzer) olmak üzere dört farklı yaprakbiti türü tespit edilmiştir. Yine benzer şekilde Doğu Akdeniz Bölgesi turunçgil bahçelerinde de bu türler saptanmış, A. spiraecola ve A. gossypii' nin en sık görülen türler olduğu belirtilmiştir (Satar \& Uygun, 2011). Yaprakbitlerinin ilkbahar döneminde ortaya çıktığı ve en yüksek bulaşıklığa nisan-mayıs aylarında ulaştığı belirlenmiştir. İlerleyen zamanda gerek sıcaklık artışı ve gerekse taze sürgün oluşumunun durması nedeniyle yaprakbiti popülasyonu artmamıştır (Şekil 3 ve Şekil 4).

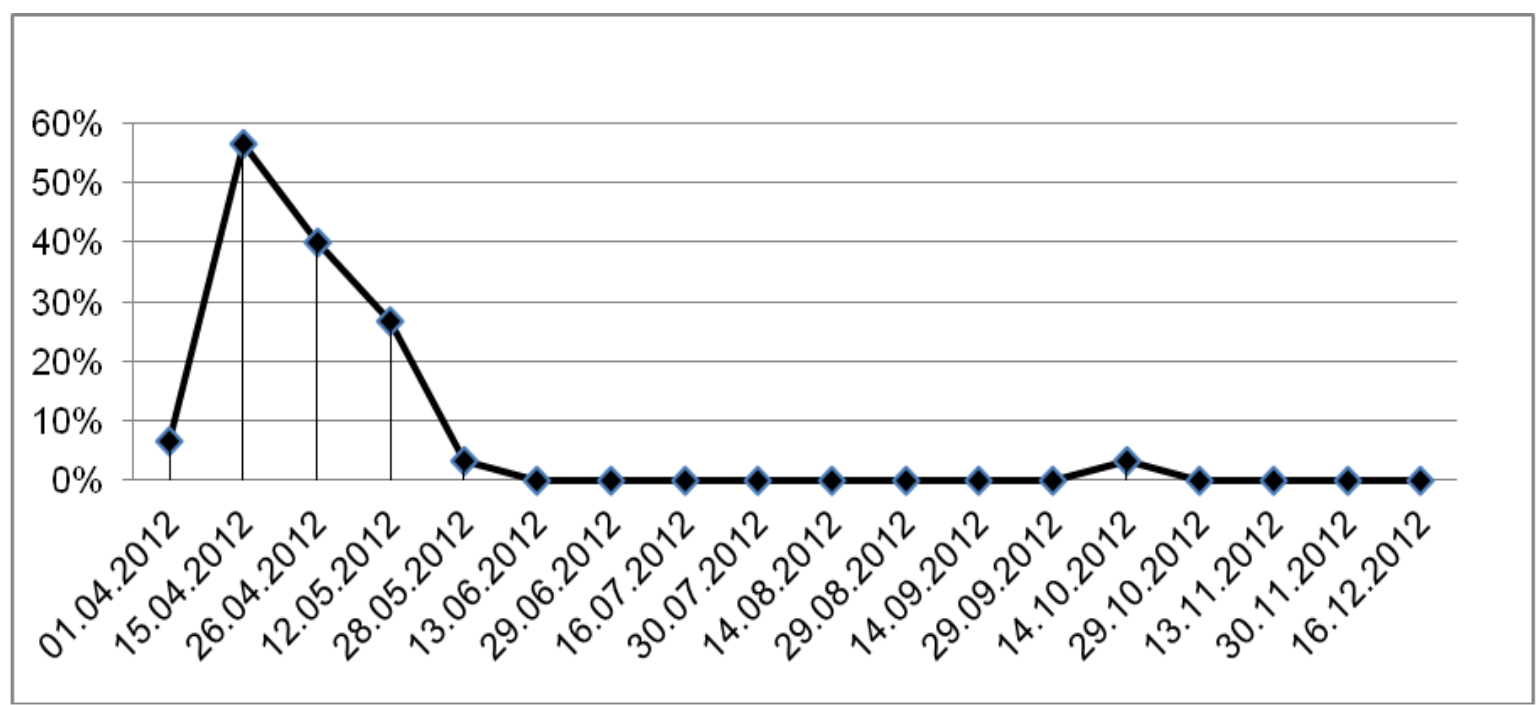

Şekil 3. Aydın il merkezindeki turunç ağaçlarında Aphididae türlerinin bulaşıklık oranları (2012). 


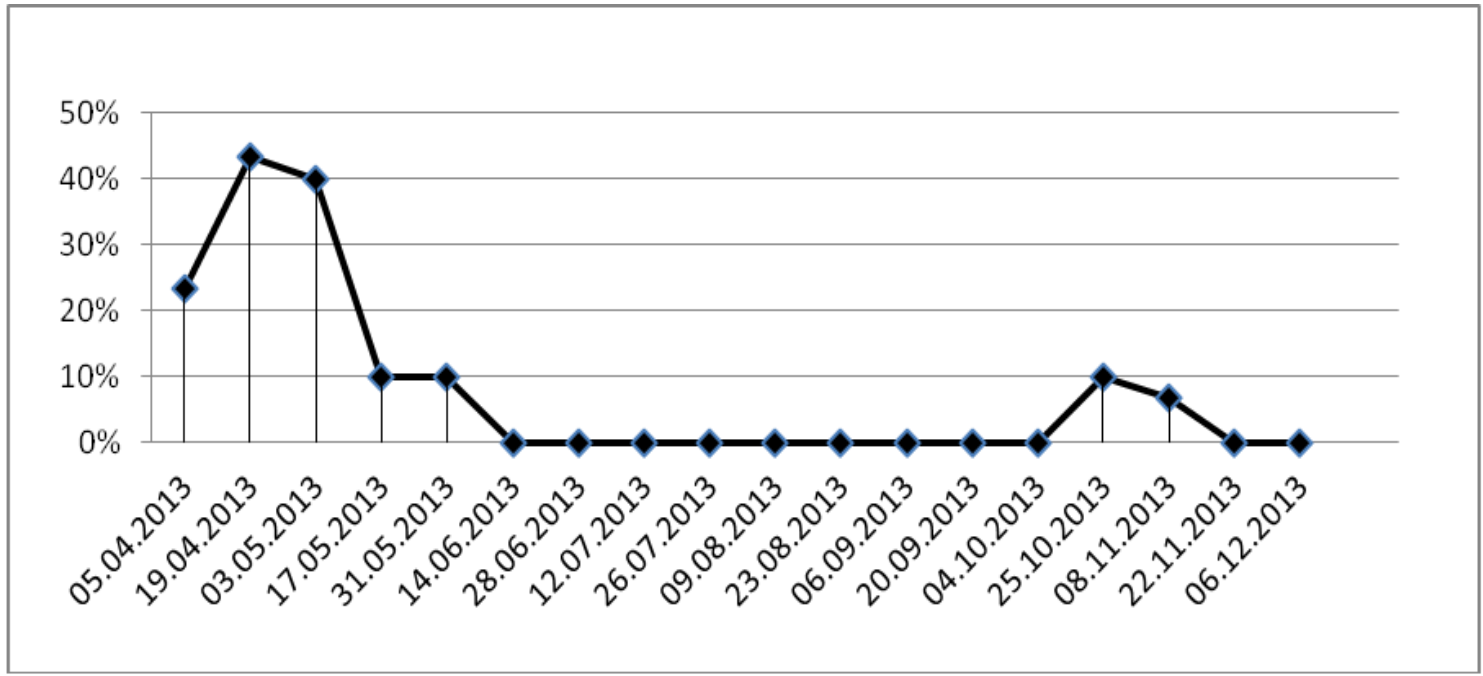

Şekil 4. Aydın il merkezindeki turunç ağaçlarında Aphididae türlerinin bulaşıklık oranları (2013).

Yaprakbitlerinin doğal düşmanları arasında, predatörleri olarak; Syrphidae familyasına bağlı sinek larvalarının etkili olduğu görülmüştür. Ancak herhangi bir Syrphidae ergini gözle kontrol sırasında görülmemiştir. Ayrıca, görülen larvalar yaprakbiti üzerinde kültüre alınmış, ancak ergin Syrphidae elde edilememiştir.

Yine yaprakbiti predatörü olarak; Adalia fasciatopunctata (Mulsant), Oenopia (Synharmonia) conglobata (Linnaeus), Adalia bipunctata (Linnaeus), Coccinella septempunctata (Linnaeus) (Coleoptera: Coccinellidae) belirlenmiştir. Yaprakbiti parazitoiti olarak; Binodoxy angelicae ve Lysiphlebus testaceipes (Hymenoptera: Braconidae) türleri belirlenmiştir. Elde edilen parazitoit sayıları çok düşük düzeylerde kaldığı için parazitlenme oranı hesaplanmamıştır.

\section{Aleyrodidae familyası ile ilgili bulgular}

Aleyrodidae familyasına bağlı zararlı tür olarak Turunçgil pamuklu beyazsineği Aleurotrixus floccosus (Maskell) belirlenmiştir. Özer \& Kısmalı (2003), İzmir İli turunçgil alanlarında A. floccosus ile D. citri' nin aynı ağaç üzerinde birlikte bulanabildiğini belirtmişlerdir. Bu çalışma da ise, turunç ağaçları üzerinde D. citri'ye rastlanmamıştır. 2012 yılında yapılan sayımlarda $A$. floccosus popülasyonun nisan ayından başlayarak arttığı ve 29.06.2012 tarihinde yaprak başına 37 bireyle (nimf-pupa) en yüksek popülasyona ulaştığı görülmüştür. Bu tarihten sonra $A$. floccosus sayısının giderek azaldığı ve mevsim sonunda yaprak başına 10 bireye (nimf) kadar düştüğü görülmektedir (Şekil 5).

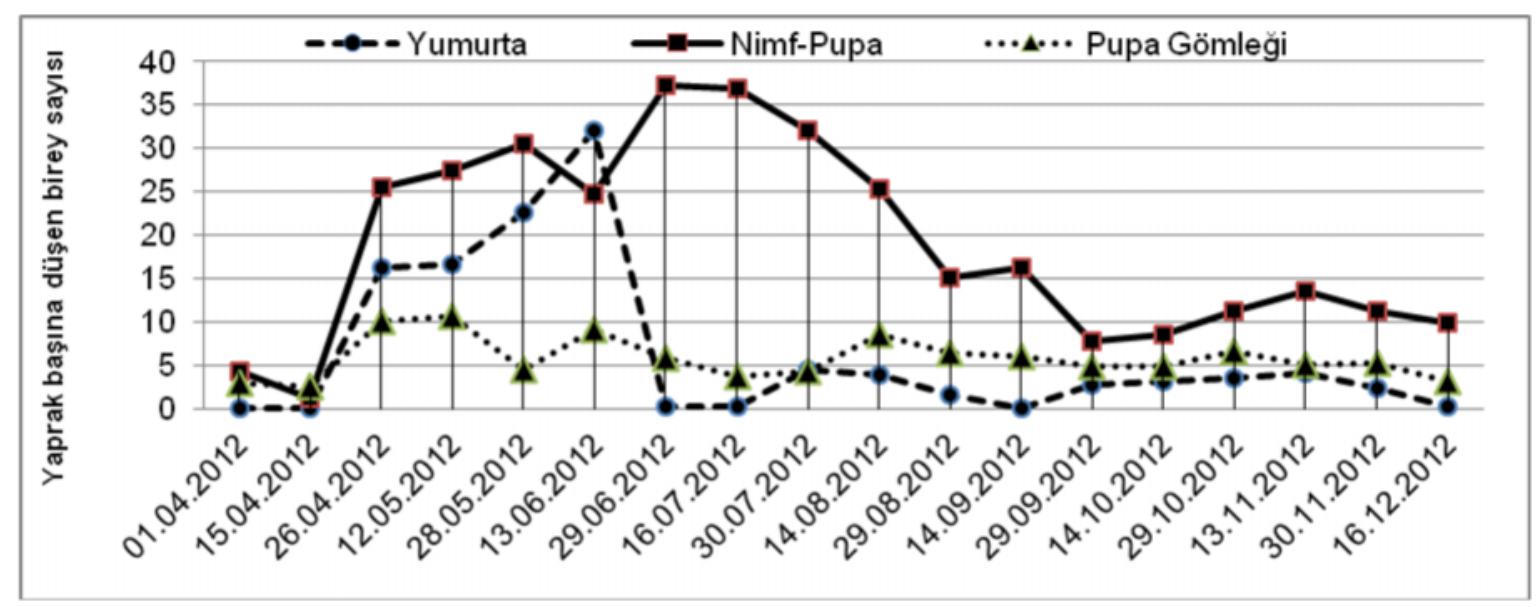

Şekil 5. Aydın il merkezindeki turunç ağaçlarında Aleurothrixus floccosus' un popülasyon dalgalanması (2012). 
Aydın İı Merkezi nde turunç Citrus aurantium L. (Rutaceae) ağaçlarında bulunan Coccoidea üst familyası ile Aphididae ve

2013 yılında yapılan sayımlarda ise $A$. floccosus popülasyonun nisan ayından başlayarak arttığı ve 28.06.2013 tarihinde yaprak başına 37 bireyle (nimf-pupa) en yüksek popülasyona ulaştığı görülmüştür. $\mathrm{Bu}$ tarihten sonra $A$. floccosus popülasyonun giderek azaldığı ve mevsim sonunda yaprak başına 12 bireye (nimf-pupa) kadar düştüğü görülmektedir (Şekil 6).

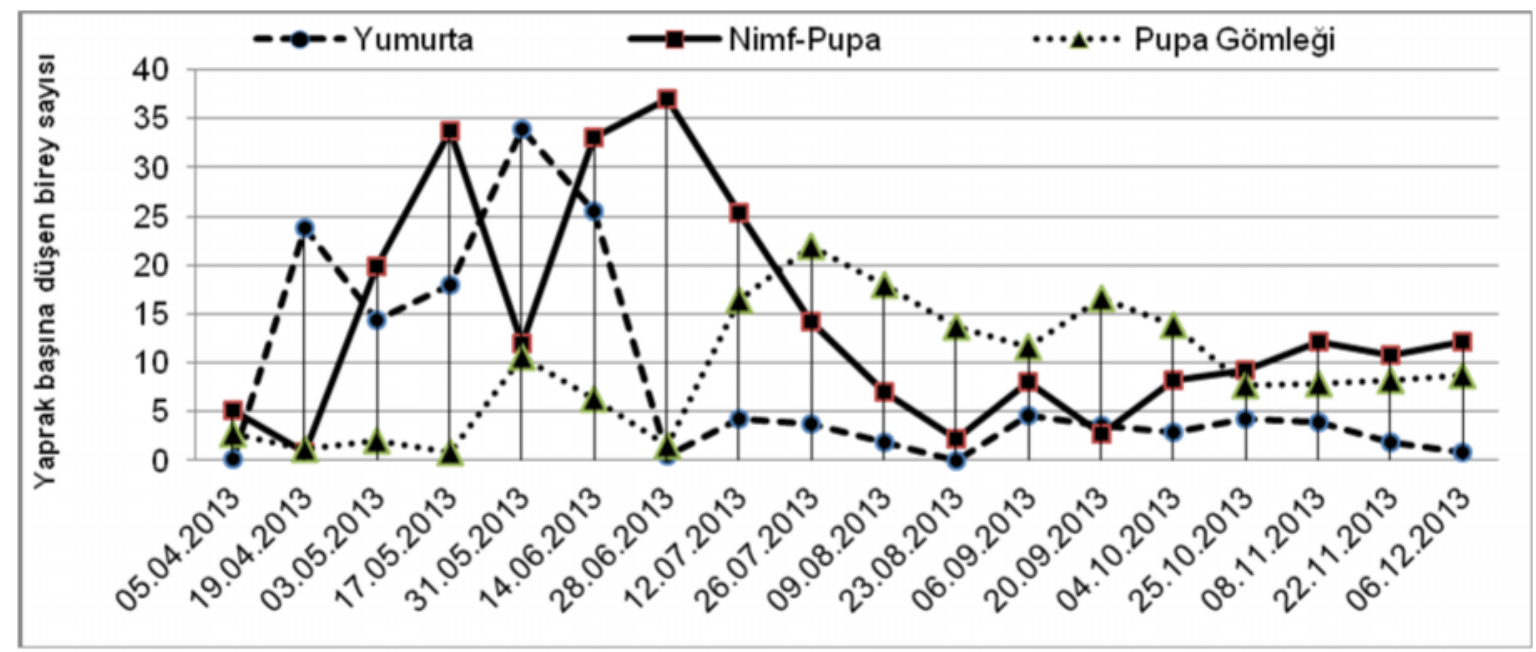

Şekil 6. Aydın il merkezindeki turunç ağaçlarında Aleurothrixus floccosus' un popülasyon dalgalanması (2013).

Her iki çalışma yılında haziran sonunda $A$. floccosus popülasyonu en yüksek seviyeye ulaşmış, ancak haziran ayından sonra zararlı popülasyonu azalan bir eğri göstermiştir. Kasım ayından sonra yapılan örneklemelerde yeni bırakılan yumurtalara rastlanmamıştır. Bu nedenle kışı geçiren nimf ve pupalar aracılığıyla üçüncü dölün bir sonraki yılın nisan ayına kadar devam ettiği tespit edilmiştir. $A$. floccosus Aydın koşullarında kışı nimf ve pupa döneminde geçirmektedir. İzmir' de yapılan bir çalışmada da kışı nimf ve pupa döneminde geçirdiği bildirilmiştir (Özer \& Kısmalı, 2003). Atina (Yunanistan)' da yapılan bir çalışmada ise $A$. floccosus' un kışı yine 3. ve 4. nimf ve pupa döneminde geçirdiği belirtilmiştir (Katsoyannos et al., 1997). Bildirilen bu sonuçlar, bu çalışmada elde edilenlerle benzerlik göstermektedir.

Bu çalışmada, parazitoitli Aleurotrixus floccosus' un kültüre alınan bireylerinden Cales noacki (Howard) (Hym.: Aphelinidae) parazitoit çıkışları gerçekleşmiştir. Parazitoitli bireylere genellikle eski yaprakların alt yüzeyinde rastlanmaktadır. Ülkemizde Ege Bölgesi' nde yapılan bir çalışmada da $C$. noackii' nin A. floccosus' un baskı altına alınmasında etkili bir parazitoit olduğu bildirilmiştir (Koçlu \& Yoldaş, 2007). C. noacki' nin, A. floccosus' un spesifik parazitoiti olduğu ve bölge şartlarına iyi uyum sağladığı ve başka bir parazitoit türünün bulunmadığı düşünülmektedir. Bu düşünceyi destekler nitelikte, Doğu Akdeniz Bölgesi' nde yapılan bir çalışmada, C. noacki' nin ana konukçusu durumunda olan $A$. floccosus popülasyonunun yeterince yüksek olmasından dolayı başka bir konukçuya gereksinim duymadığı belirtilmiştir (Vatansever \& Ulusoy, 2005). Bunun yanı sıra, Chermiti \& Onillon (1995), yayınlarında $A$. floccosus'un spesifik parazitoiti olan C. noacki'nin zararlıyı baskı altına almada çok başarılı olduğuna dikkat çekmiştir.

Bu çalışmanın yürütüldüğü 2012-2013 yıllarında, A. floccosus' un C. noacki ile parazitlenme oranları mevsim süresince izlenmiş ve eylül ayında en yüksek düzeyde olduğu görülmüştür. Aynı zamanda Chrysoperla carnea (Stephens) (Neuroptera: Chrysopidae) larva ve erginlerinin turunç ağaçları üzerindeki $A$. floccosus ile beslendiği tespit edilmiştir. Özellikle $C$. carnea larvalarının, $A$. floccosus' un nimfleriyle beslendiği gözlemlenmiştir. Temmuz ayından başlayarak sonraki tüm sayımlarda $C$. carnea yumurtalarının ve larvalarının turunç ağaçlarındaki popülasyon yoğunluğunun giderek artığı saptanmıştır. 
Elde edilen bu bulgular topluca değerlendirildiğinde, Aydın ilinde süs bitkisi olarak değerlendirilen turunç ağaçlarında birçok zararlının bulunduğu görülmektedir. Bunların üzerinde birçok doğal düşman belirlenmiş olsa da, söz konusu zararlıları baskı altında tutamadığı gözlenmiştir. Özellikle, Coccidae ve Aleyrodidae familyasına bağı zararlıların nemli ortamlarda daha yüksek popülasyonlara ulaştığı bilinmektedir. Son yıllarda Aydın ili çevresinde yeni yapılan barajlar ve ovada pamuğa göre daha sık sulama gerektiren mısır üretiminin ekonomik nedenlerle pamuğa tercih edilmesiyle orantılı nemin arttığı bilinmektedir. Şehir içerisinde yolların tozlu ortamının şehir içi trafiğinin de etkisiyle turunç ağaçları üzerini kapladığı ve bu durumun doğal düşmanların etkisini düşürdüğü söylenebilir. Bunlara ek olarak, yaz aylarında hemen her gün yapılan sivrisinek mücadelesine yönelik ilaçlamaların da doğal düşmanları olumsuz etkilediği bir gerçektir. Sonuç olarak, Aydın ili şehir merkezinde süs bitkisi olarak bulunan turunç ağaçlarında zarar yapan bu zararlılarla mücadelede uygun yöntemlerin belirlenmesi için daha ayrıntılı çalışmalar yapılmalıdır.

\section{Teşekkür}

Bu çalışmada örneklenen Coccoidea üst familyasına bağı türlerin teşhisini yapan Prof. Dr. Bora KAYDAN' a (Ç. Ü. İmamoğlu MYO, İmamoğlu, ADANA), Aphididae örneklerinin teşhisini yapan Dr. Işıl ÖZDEMIR' e (Merkez Zirai Mücadele Araştırma Enstitüsü, ANKARA), Coccinellidae familyası türlerinin teşhisini yapan Prof. Dr. Nedim UYGUN' a (Ç. Ü. Ziraat Fakültesi, Bitki Koruma Bölümü, ADANA), Braconidae familyası türlerinin teşhisini yapan Prof. Dr. Ahmet BEYARSLAN' a (Bitlis Eren Ü. Fen Edebiyat Fakültesi, Biyoloji Bölümü, BiTLIS) ve Aleyrodidae örneklerinin teşhisini yapan Prof. Dr. M. Rifat ULUSOY' a (Ç. Ü. Ziraat Fakültesi, Bitki Koruma Bölümü, ADANA) teşekkürü bir borç biliriz.

\section{Yararlanılan Kaynaklar}

Aytaş, M., R. Yumruktepe \& C. Mart, 1997. Doğu Akdeniz Bölgesinde turunçgillerde zararlı kırmızı kabuklubit Aonidiella aurantii' nin mücadele metotlarının geliştirilmesi. TÜBITAK Tarım Orman ve Gıda Teknolojileri Araştırma Grubu, Adana, Proje no: TOGTAG- 1252.

Chermiti, B. \& J.C. Onillon, 1995. Premiers resultats sur L'implantation et L'acclimatation en Tunisie de Cales noacki How. (Hym., Aphelinidae), parasitoide D' Aleurothrixus floccosus Mask. (Hom., Aleurodidae). OIBC/ OILB Bulletin, 18(5): 56-67.

Gücük, M. \& Z. Yoldaş, 2000. Aphis gossypii Glover (Homoptera: Aphididae)' nin parazitoiti Aphidius colemani Viereck (Hymenoptera: Braconidae)' nin bazı biyolojik özellikleri üzerinde araştırmalar. Türkiye Entomoloji Dergisi, 23 (2):143-152.

Katsoyannos, P., K. Ifantis \& D.C. Kontodimas, 1997. Phenology, population trend and natural enemies of Aleurothrixus floccosus (Maskell) (Hemiptera: Aleyrodidae) at a newly invaded area in Athens. Greece Entomophaga, 42 (4): 619-628.

Kaydan, M.B., S. Ülgentürk, \& L. Erkılıç, 2007. Checklist of Turkish Coccoidea species (Hemiptera: Coccoidea). Yüzüncü Yıl University, Journal of Agricultural Science 17: 89-106.

Koçlu, T. \& Z. Yoldaş, 2007. Ege Bölgesi turunçgillerinde zararlı Aleurothrixus floccosus' un Cales noacki H. (Hymenoptera: Aphelinidae) ile biyolojik savaş olanaklarının araştıııması. Türkiye Entomoloji Dergisi, 31 (3): 203-213.

Lodos, N., 1986. Türkiye Entomolojisi II. Genel, Uygulamalı ve Faunistik. Ege Üniversitesi, Ziraat Fakültesi Yayınları, No: $429,580 \mathrm{~s}$.

Öncüer, C., 1974. Ege Bölgesi turunçgil bahçelerinde zararlı Coccus türlerinin tanınması, yayılışları ve doğal düşmanları üzerinde araştırmalar. Bitki Koruma Bülteni, Ek yayın, 1-59.

Öncüer, C. \& Z. Yoldaş, 1988. İzmir Illi turunçgil bahçelerinde yeni bir zararlı: Parabemisia myricae (Hom: Aleyrodidae). Türkiye Entomoloji Dergisi, 12 (4): 231-233.

Özer, G. \& Ş. Kısmalı, 2003. İzmir İli turunçgil alanlarında turunçgil pamuklu beyazsineği Aleurothrixus floccosus' un yayılışı, zararı ve popülasyon yoğunluğu üzerine araştırmalar. Türkiye Entomoloji Dergisi, 27 (1): 61-72. 
Aydın İ Merkezi nde turunç Citrus aurantium L. (Rutaceae) ağaçlarında bulunan Coccoidea üst familyası ile Aphididae ve Aleyrodidae familyaları (Hemiptera)' na bağlı türlerin saptanması, bulaşma oranlarının ve doğal düşmanlarının belirlenmesi

Satar, S. \& N. Uygun, 2011. Lysiphlebia japonica (Ashmead) (Hymenoptera: Braconidae)' nın Aphis spiraecola Patch ve Aphis gossypii Glover (Hemiptera: Aphididae) üzerinde bazı biyolojik özeliklerinin belirlenmesi. Türkiye Biyolojik Mücadele Dergisi, 2 (2): 103-118.

Soylu, O.Z., 1980. Akdeniz bölgesi turunçgillerinde zararlı olan Turunçgil Beyazsineği (Dialeurodes citri Ashmead)' nin biyolojisi ve mücadelesi üzerinde araştırmalar. Bitki Koruma Bülteni, 20 (1-4): 36-53.

Şişman, S. \& S. Ülgentürk, 2010. Scale insects species (Hemiptera: Coccoidea) in the Turkish Republic of Northern Cyprus. Turkish Journal of Zoology, 34 (2010): 219-224.

Ulusoy, M.R. \& N. Uygun, 1996. Doğu Akdeniz Bölgesi turunçgillerinde potansiyel yeni zararlı: Aleurothrixus floccosus (Maskell) (Homoptera: Aleyrodidae) ve Paraleyrodes minei laccarino (Homoptera: Aleyrodidae). Türkiye Entomoloji Dergisi, 20 (2): 113-121.

Ülgentürk, S. \& M.B. Kaydan, 2006. Bazı unlubit türleri ile parazitoit Anagyrus pseudococci (Hym.: Encyritidae) arasındaki biyolojik ilişkiler ve unlubit avcısı Cryptolaemus montrouzieri (Col.: Coccinellidae) ile etkileşimleri. TÜBITAK Tarım, Ormancılık ve Veterinerlik Araştırma Grubu, Ankara, Proje no: TOVAG-3261.

Uygun, N., İ. Karaca, R. Ulusoy \& D. Şenal, 2001. Turunçgil zararlıları ve entegre mücadelesi. (Ed. N. Uygun, Türkiye Turunçgil Bahçelerinde Entegre Mücadele), TÜBITAK - TARP yayınları, 157s.

Uygun, N., M.R. Ulusoy, İ. Karaca \& S. Satar, 2010.Meyve ve Bağ Zararlıları. Özyurt Matbaacılık, ISBN: 978-605397-067-5, Adana, 347s.

Vatansever, G. \& M.R. Ulusoy, 2005. Parazitoit Cales noacki Howard (Hymenoptera: Aphelinidae)' nin konukçuları ve doğadaki yıllık döl sayısı. BAÜ Fen Bilimleri Enstitüsü Dergisi, 7 (1): 12-16.

Yumruktepe, R. \& N. Uygun, 1994. "Doğu Akdeniz Bölgesi turunçgil bahçelerinde saptanan yaprakbiti (Homoptera: Aphididae) türleri ve doğal düşmanları 1-12". Türkiye III. Biyolojik Mücadele Kongresi Bildirileri, Cilt I, (25-28 Ocak 1994, İzmir), 574 s.

Zümreoğlu, A., E.P. Önder, O. Ulu, \& N. Saltabaş, 1985. Ege Bölgesi turunçgillerinde zarar yapan Ceroplastes rusci' nin kimyasal savaş metotları üzerinde araştırmalar. Türkiye Bitki Koruma Dergisi, 9 (4): 247-253. 